Archived version from NCDOCKS Institutional Repository http://libres.uncg.edu/ir/asu/

\title{
Appalachenan
}

во Оох

\section{Integrating Lidar, GIS And Hedonic Price Modeling To Measure Amenity Values In Urban Beach Residential Property Markets}

\author{
By: Stuart E. Hamilton and Ashton Morgan
}

\begin{abstract}
Hedonic property price models have been used extensively in the economics literature to measure the value households place on locating properties close to a given resource, such as a beach, river, or lake. This proximity premium consists of two components. First, property owners derive benefit from living close to the resource for access purposes. Second, they also derive benefit from the view of the resource. Critical to the analyses is the identification and measurement of these two components. We augment previous research by providing more accurate and objective measures of access and view for urban beach residential properties. Using GIS, we calculate the distance from each property to the nearest designated public access point. Using lidar data, we calculate the ocean view from each property. These measures are then integrated into a hedonic property price model to disentangle and estimate households' willingness to pay for beach access and view.
\end{abstract}

Hamilton, S. E. and Morgan, O.A. (2010) "Integrating Lidar, GIS And Hedonic Price Modeling To Measure Amenity Values In Urban Beach Residential Property Markets." Computers, Environment and Urban Systems, 34(2): 133-141 (ISSN: 0198-9715). Version Of Record Available At www.sciencedirect.com 


\section{INTRODUCTION}

There is a long history of using hedonic property price models to investigate the effects of amenities and disamenities on the sales prices of residential properties. For example, Parsons and Noailly (2004) measured the implicit amenity value to households from locating properties close to the beach in Rehoboth, DE, while Bensen, Hansen, Schwartz, and Smersh (1998) examined households' willingness to pay a premium for properties with proximity to both lakes and the ocean in Washington State. Also, Bin and Polasky (2004), and Morgan (2007) measured the implicit risk associated with properties located in the Special Hazard Flood Areas across counties in North Carolina and Florida, respectively.

Hedonic models are based on the economic theory of consumer behavior. The theory suggests that households value the characteristics of a good rather than the good itself. In hedonic property price valuations, the price of a residential home is a function of its structural attributes (such as the number of bathrooms, lot size, and age), and also its locational attributes and amenities (such as distance to the beach, view, and air quality). In the hedonic framework, assuming a competitive housing market, the implicit prices (values) of these attributes and amenities can be estimated by observing the prices of differentiated properties and their structural and locational characteristics.

While tax records on sold properties provide the researcher with the majority of the properties' structural attributes for use in the model, locational attributes are not readily available. For example, studies examining the implicit value attributable to living close to a given resource, such as a beach or lake, require information that captures a property's proximity and aesthetic qualities. Such information is not available in a property appraiser's database.

This creates a problem for the researcher. Earlier studies attempted to circumvent this problem by using a standard measure of linear distance from the property to the resource to capture the amenity value ( [Boyle and Kiel, 2001], [Parsons and Noailly, 2004], [Parsons and Powell, 2001] and [Pompe, 2008]). The reasoning is that properties closer to the resource sell for a premium, so the value of living close to the amenity can be implicitly estimated, holding all other factors constant. While this serves as a useful proxy, its simplicity fails to account for the complex nature of the benefits associated with living close to a resource. Essentially, we argue that an amenity value, or the benefit of living close to a resource, is comprised of two components. First, access is important. Other studies have shown that households are willing to pay a premium for properties close to a resource (see [Lansford and Jones, 1995], [Parsons and Noailly, 2004] and [Pompe and Reinhart, 1995]; Bin et al., 2004). These studies indicate that there is a value associated with being able to access a beach or a lake for recreational and leisure purposes. However, as discussed by Bourassa, Hoesli, and Peng (2003), another component of amenity value is the view of the resource itself. Again, some previous studies indicated that view and property values are positively correlated (see [Bond et al., 2002], [Bourassa et al., 2003] and [Tse, 2002]). Further, Bin and Kruse (2006) reasoned that, having controlled for access, view will capture most of the residual amenity value.

However, again, a property's view is not a component of an appraiser's database. Some research has accepted the challenge and attempted to control for view in the hedonic 
framework by using a single dichotomous variable equal to one if the property has a view of the resource, and zero otherwise ( [Bond et al., 2002], [Doss and Taff, 1996] and [Pompe and Reinhart, 1995]) More recently, studies used a view scale to try and provide a more continuous valuation. For example, Bensen et al. (1998) used three dummy variables for scope (ocean front, unobstructed ocean view, and partial ocean view) to capture property views in Washington State, while Bourassa et al. (2003) used narrow, medium, and wide definitions of view to indicate the quality of a lake view on property values in Auckland, New Zealand. While empirically preferable to a single dichotomous parameter of view, these scope measures suffer from the subjective nature of the classification. For example, an ocean front property may not provide a better view of the resource than a property situated one or two blocks back. Along many coastlines, dunes may obstruct the view of some ocean front properties, while more elevated in-land properties have an improved view. Unless the researcher can physically inspect each property and gauge the applicable level of view for each home, these qualitybased view measures may fail to adequately capture each property's true view. For these reasons, the utilization of lidar is preferred over traditional methods of obtaining view as a continuous measure can be obtained for each assessed property.

Recent advances in laser ranging combined with Geographic Information Systems (GIS) facilitates a more precise and objective measure of view for use in hedonic models. Lidar data provides information on the topographic surface of the coastal area, including all structures, dunes, and vegetation. A view from each property can then be constructed that accurately accounts for other structures and vegetation that may obstruct a property's view of the shoreline. As such, capturing a property's view using lidar data in a GIS environment provides an objective and continuous measure of each property's view that circumvents many of the problems inherent in previous view classifications.

The purpose of this research is to incorporate GIS and lidar data to construct beach access and beach viewshed variables and include both in a hedonic property price model to separately estimate the two amenity values. In constructing the viewshed variable, we follow work by Paterson and Boyle (2002) and Bin, Crawford, Kruse, and Landry (2008) by using lidar data to construct a continuous measure of viewshed. As such, the viewshed parameter measures the view from each property to capture the home's aesthetic quality. A priori expectations are that households are willing to pay a premium for homes with a greater view of the Gulf of Mexico, having controlled for all other structural and locational characteristics. For access, we make a departure from other hedonic studies that capture access as the linear distance to the shoreline. Instead, to measure access to the beach, we construct the linear distance from each property to the nearest beach public access point. We argue that for many coastal communities, residents must access the beach at designated access points, so this should be controlled for in the modeling process. A priori expectations are that households are willing to pay more for properties with improved beach access, all else being equal. Our data provide an interesting opportunity to observe, through the hedonic framework, how households value access. In communities with restricted beach access, do households value the network access distance or do they perceive access benefits to accrue via the linear distance to the shoreline? Economic theory suggests, as individuals seek to maximize utility, they will prefer properties that provide better access to the shoreline, all else being equal. Therefore, in restricted-access communities, 
having controlled for all other factors, individuals should be willing to pay a premium for properties located closer to designated access points, even if these properties are located farther from the shoreline.

\section{STUDY AREA}

The study area is the urban area of Pensacola Beach, Florida, a barrier island, located in the western segment of Florida's Panhandle. Pensacola Beach's location on the shores of the Gulf of Mexico and the claim of having the "whitest beaches in America" make it a popular tourist destination and desired property location (Fig. 1). There is an approximate two-mile stretch of residential homes along Pensacola Beach, with 281 single-family residences located on the Gulf side of the peninsula. In the study, we do not include properties located on the Bay-side of Pensacola Beach. This avoids the analytical complications of quantifying the view of two different resources, as there is a distinct premium for properties located on the Gulf side of the beach. Also, as other segments of the beach are for commercial use or contain multi-family units, they are not analyzed within this study. Merging GIS data, lidar data, and sales transactions data for properties sold between 1998 and 2007, we generated a sample of 101 homes for use in estimation. Property price and structural attribute data come from the Pensacola Association of Realtors (PAR) database of property transactions. ${ }^{1}$ Sales prices are adjusted to 2007 prices using the consumer price index for housing. The following sections discuss utilizing GIS and lidar data to capture each property's view and access. We then present the hedonic model. Finally, we discuss the model results together with concluding remarks. 

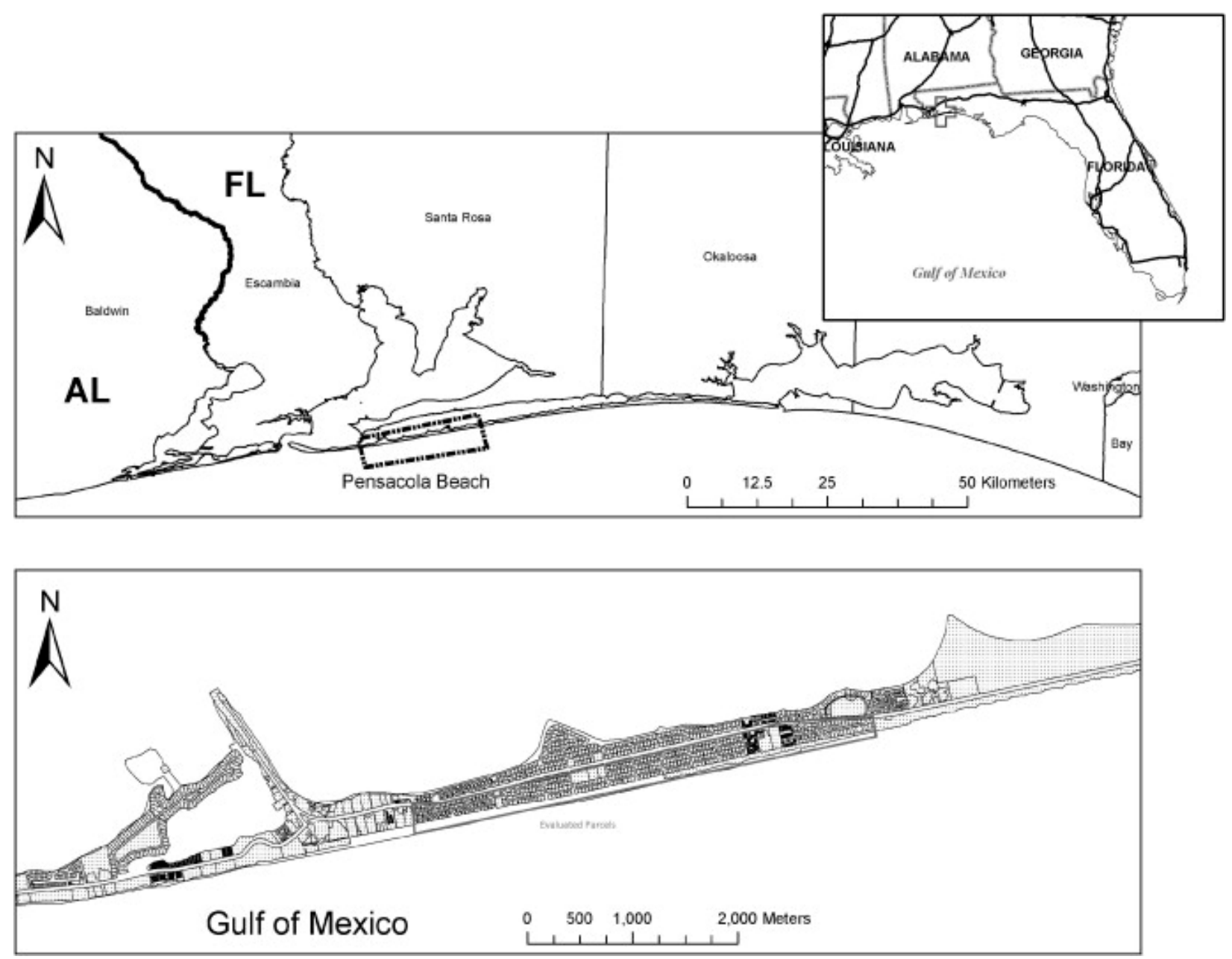

Fig. 1. Study area.

\section{LIDAR DATA}

Accurately capturing beach view is a critical component in the analysis. We use lidar data to provide a continuous and objective measure. Airborne lidar systems are comprised of three components that allow for accurate measures of elevation over large swaths: (i) a laser range finder and sensor for accurate distance measures; (ii) an inertial navigation unit that constantly monitors the orientation of the laser sensor and corrects for errors that would be caused by the pitch, yaw and roll of the aircraft; and (iii) a DGPS that constantly measures the location of the laser sensor in three-dimensional space (Deronde et al., 2006). Lidar sensors typically generate three-dimensional mass-point structures that record not only the elevation of the objects detected by the laser pulse but the multiple return signals that may be returned to the sensor in addition to the initial return (Wehr \& Lohr, 1999). For example, in environments with few structures or vegetation (such as a beach-face or desert), the only return would be the actual ground location. In an area covered by forest or other vegetation, a single emitted pulse may 
return numerous differing returns as it travels through the canopy or vegetation to the ground. This multiple return facet of lidar sensors allows for the creation of bare-earth digital models as well as models of surface features that include structures.

Lidar data are highly suitable for any analysis that requires not only a highly accurate topographic representation of the environment but also a highly accurate vertical representation of the structural component of a landscape. Indeed, lidar data may be the only option to conduct a mass view analysis in an urban environment. Other elevation technologies such as IFSAR, SRTM, traditional rod and laser survey, and even stereo-photography lack either the ability to accurately measure structural features in the landscape, the required horizontal and vertical resolution to account for small obstructions, or the ability to collect a suitable amount of elevation when taking into account cost and access considerations. SRTM and IFSAR lack the spatial resolutions required and stereo-photography may lack the spatial resolution dependent on the survey quality. The cost of deriving all the structural information from stereo-photography is also prohibitive. A traditional laser survey would be prohibitively expensive and timeconsuming if it attempted to capture the elevation and structural data for an area of many square miles even assuming the surveyor had all the required property access permissions.

For our study, the Leica ALS-50 instrument collected elevation data during June and July of 2006 and was flown by 3001 Inc. under the supervision of a licensed surveyor. These data were provided in LAS format by Escambia County GIS. Metadata and flight parameters were calculated and provided by NOAA (2007). The vertical Root Mean Square Error (RMSEz) of the elevation data in open areas was determined to be $13 \mathrm{~cm}$ using the ASPRS guidelines for vertical reporting of lidar data accuracy at the 95\% confidence interval. Within all land cover categories, the RMSEz increased to $33 \mathrm{~cm}$. The RMSEz was determined utilizing a sample of 101 pre-established ground control points. The testing method is consistent with those specified in the National Standard for Spatial Data Accuracy and ASPRS and was conducted by Dewberry \& Davis LLC., across five different land cover categories. The RSME of non-forested and lightly vegetated beach environments such as those found in the study area falls between $13 \mathrm{~cm}$ and $33 \mathrm{~cm}$ for this dataset. One of the primary benefits of utilizing lidar data is the relatively small level of vertical error when compared to other elevation products. Assuming an RMSEz of $33 \mathrm{~cm}$ lidar data can place an observer and all potential structures and vegetation that may alter the view of the observer with a sub-meter level of accuracy. This combined with the potential for creating high-resolution horizontal grids of each location minimizes errors in the viewshed analysis that are caused by small changes in the elevation or location of structures and vegetation. All lidar data utilized in this study and resultant elevation model are referenced horizontally to UTM zone 16 N utilizing NAD 1983, and vertically to NAVD 1988.

The data were processed according to procedures developed by Houser, Hapke, and Hamilton (2008) and Houser and Hamilton (2009) in their analysis of costal impacts of storms that included Pensacola Beach. The lidar mass-point files were converted to continuous grid data using ArcGIS. The resolution of each elevation grid-derived LAS file was set to $1 \mathrm{~m}$ to capture vegetation and features such as the shoreline berm. The bare-earth grid was created utilizing the Visual Learning Systems' (VLS) bare-earth algorithm. The first-return elevation grid was interpolated using the inverse distance weighting (IDW) equation: 
(1)

$$
\overbrace{Z}\left(X_{0}\right)^{n}=\frac{\sum_{i=1}^{n} Z\left(X_{i}\right) \cdot d_{i j}^{-r}}{\sum_{i=1}^{n} d_{i j}^{-r}}
$$

IDW was required to assign cells a value that had missing elevation values due to the zigzag manner of lidar returns (Deronde et al., 2006). The power function, $r$, was set to 3 to negate the influence of more distant sample points and the neighborhood function, $n$, was set to 4 to allow only the closest neighbors to determine the actual elevation of cells without a return. It should be noted that most $1 \mathrm{~m}$ cells contained at least one elevation value so the interpolation with the above parameters merely assigned values to these empty cells using the closest four points, with the closest points having the heaviest influence.

\section{DETERMINING OBSERVER LOCATION}

In capturing beach view for each property, we first needed to determine a common desired observer location in each property from which to make the measurement. To do this, the building footprints were extracted from the lidar data using the VLS bare-earth algorithm. Identification (and elimination) of structures is a necessary part of the process of creating a bare-earth elevation model. Within the study area, building footprints were also digitized manually from orthorectified 2006 imagery of Pensacola Beach. These polygonal building footprints were then joined back to the property appraisers' data that contains information on the roof structure. At this point, the footprint file was clipped to remove all property with usage other than single-family residential. The next step was to attribute each identified roof structure with an elevation variable from the first-return lidar elevation model. This was achieved by averaging the value of all first-return elevation readings with the polygonal outline of the roof structure. Upon achieving a mean value for each roof structure, the polygonal data were converted to point data, and the point location was manually moved to the Gulf side of the property just outside of the roof polygon. This allows an optimal view to be recorded during the view analysis and prevents any property from blocking its own view of the amenity.

The desired observer location is the window level of the highest livable story of each home, with the observer located at the Gulf side of each property. By utilizing a top-down method for recording the observer location, difficulties related to variable storied homes, homes built on pylons, and homes built on raised fill are mitigated when calculating the most desirable view observer location for viewshed analysis. Earlier studies that utilized lidar-derived view within economic models used a standard distance from the elevation of the roof to place the observer (Bin et al., 2008). This study expands on the process of using a standard offset to derive an observer location from a roof height by not assuming a common roof type, but actually using the lidar data and property data to delineate roof type, and hence adjust the offset according to the roof structure. The first-return lidar data allows not only for depiction of the horizontal location of a roof but allows for measures of the vertical structure of the roof type. 
Two markedly different roof types, and hence two different observer locations exist on singlefamily structures located in Pensacola Beach. Roof type one was assigned to flat roofs and Mansard style roofs in which the observer height is only slightly below the lidar derived mean roof height. These roof types were noted in the property appraiser data and further verified in the lidar point cloud by observing the maximum and mean elevation difference of all laser firstreturns from the roof surface. A nominal difference in elevation range indicates a flat style roof and hence a smaller offset is required for the spot elevation. The observer location offset distance for roof type one is $1.5 \mathrm{~m}$ below the mean height of the roof structure. That is, the observer location is assumed to be $1.5 \mathrm{~m}$ below the mean height of the roof. The second type of roof structure common on single-family homes in Pensacola Beach comprised hip roofs, gabled roofs, and more complex combination roofs. A substantial difference in the mean and maximum values indicates a non-flat style roof, and hence a larger offset is required for the observer location correction. The offset distance for roof type two is $3 \mathrm{~m}$ below the mean height of the roof structure. That is, the observer location is assumed to be $3 \mathrm{~m}$ below the mean height of the roof. Each spot elevation was then compared back against the bare-earth lidar model to ensure than the all spot elevations are at least $1 \mathrm{~m}$ above the ground level determined for each structure.

\section{CALCULATING VIEW}

Determining the view of all 101 properties utilized the lidar derived three-dimensional first-return grid and a point layer of three-dimensional observer locations. In addition to the first-return topographic DEM and the spot elevation point file, a digital elevation model of the Gulf was required to allow the views to continue out over the surface of the water. An artificial elevation model was created from the shoreline to $1500 \mathrm{~m}$ out into the Gulf of Mexico, and given the elevation value of NAVD $88.0 \mathrm{~m}$. The first-return lidar-derived topographic model and the Gulf surface water model were then combined using simple cartographic modeling techniques to create a continuous elevation model that includes the study area and the ocean surface (Fig. 2). This elevation model, containing all structures and elevation, was the basis for delineating each property's view. 


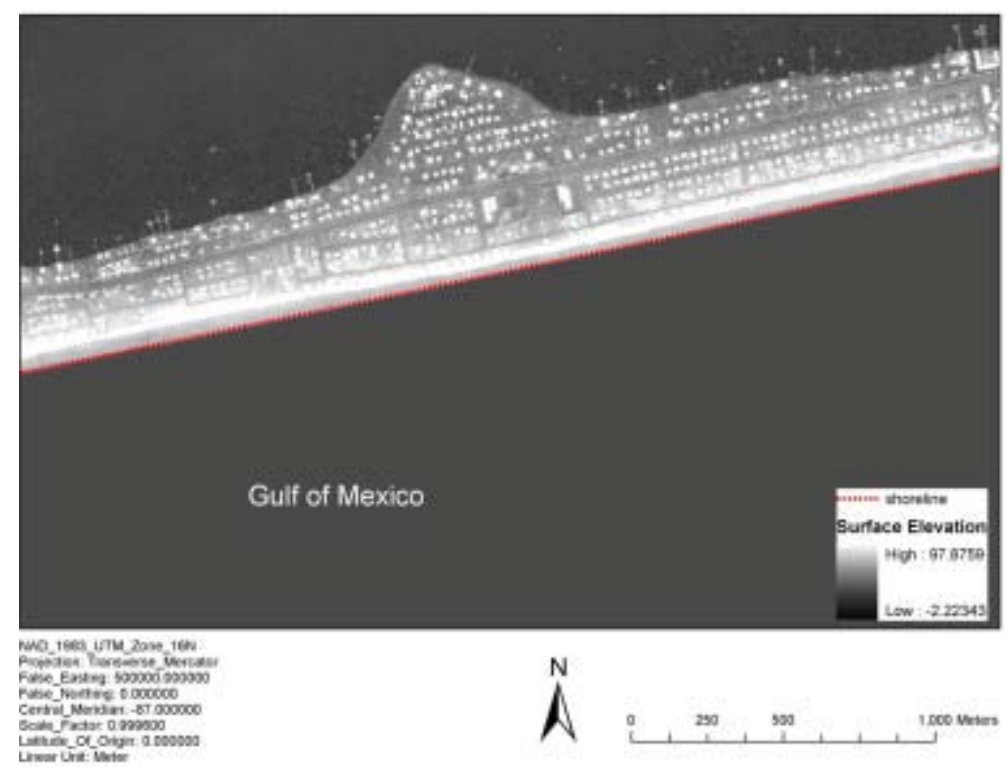

Fig. 2. Surface elevation model, shoreline and ocean surface.

Although intuitive to the individual, the quantification view can utilize numerous differing metrics. The most common are variants of square area viewable or an angular measure of view based on a radii measure. The decision to measure view as angle of view or area of view does not alter the analysis as presented. As it is the relative measure of view that is critical either metric will suffice as an observer location with twice the view angle of another will have the same linear relationship in viewable area (beyond a nominal distance from the observer location). For this analysis view angle is the metric utilized as the measure of view in keeping with other measures of view in lidar derived viewscape analyses ( [Bin et al., 2008] and [Paterson and Boyle, 2002]). The 101 property viewsheds were calculated using radii of $1000 \mathrm{~m}$ from the spot location of each individual property. The measurement of an individual property's view in this study is an angular measurement noting the amount of ocean and beach visible from each individual property.

Due to the linear nature of the shoreline (Fig. 2) in this area, the maximum view angle (MVA ${ }^{\circ}$ of the Gulf of Mexico is180. Although it is theoretically possible to have a MVA ${ }^{\circ}$ greater than 180, a structure would have to extend beyond the shoreline into the Gulf to achieve this level of view, and this does not occur at our area site of interest. A severely meandering shoreline would also theoretically allow for a $\mathrm{MVA}^{\circ}$ greater than 180 but this also does not occur. Within the study area, the actual maximum of any individual property's view angle (IPVA ${ }^{\circ}$ ) is 173 deg, and the IPVA $^{\circ}$ minimum is 0 deg. Within the study area, any IPVA ${ }^{\circ}$ is primarily obstructed by other structures, trees, and an artificial shoreline berm, all of which are depicted in the lidar first-return DEM but would be omitted using other elevation products.

The ocean view from any observer location is returned by the GIS as a semi-circular grid dataset, with one representing view, and zero representing no view. The circular raster is then reclassified to remove all zero values, clipped by the shoreline, and converted to a line feature. 
The length of each property's circular line feature (IPAL) is then fed into the equation below to return an angular unit of view:

(2)

$\operatorname{IPVA}^{\circ}=\operatorname{MVA}^{\circ}\left(\frac{\mathrm{IPAL}}{\pi r}\right)$

For all 101 properties sold in Pensacola Beach between 1998 and 2007, an angular measure of view of the Gulf of Mexico was added to each individual property transaction record. This method of assigning views is similar to the method utilized in Bin et al. (2008) in their research into the role of viewscapes and flood hazards and Paterson and Boyle (2002) in their analysis of bare-earth viewshed in hedonic models. Fig. 3 demonstrates the method of calculating view. In this example, two properties are selected to demonstrate the procedure. Property ID 012 is located one block (Row 2) from the Gulf of Mexico and has a vacant lot in front of its property. By extending out radii viewfield of $1000 \mathrm{~m}$ from the spot elevation determined for this home, an angular measure of view is determined for the property. This particular property has an IPVA ${ }^{\circ}$ of 131 that means that from the observer location the property has $131 \mathrm{deg}$ of Gulf view. This is due mainly to the lack of any property obstruction directly in-between the property and the Gulf. Some of the near-shore view is blocked by vegetation on the berm and some of the view towards the edges of the view is blocked by Gulf front properties that are opposite and cattycorner to the property. Property 006 is located two blocks from the Gulf of Mexico and has a vacant property directly in front. It has an IPVA ${ }^{\circ}$ of 39 . Again, this property has substantial view of the Gulf straight-ahead but its view is far more limited due to the additional structures present on the Gulf side of the property. A summary of these data are found in Table 1.

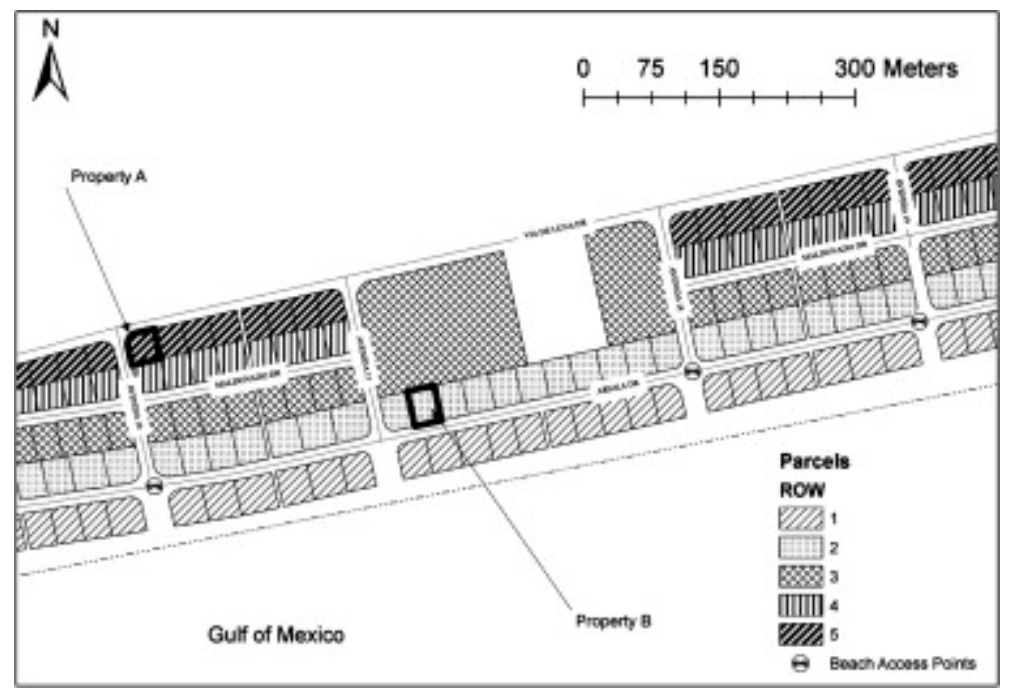

Fig. 3. Sample properties. 
Table 1

View results for Pensacola beach.

\begin{tabular}{llllll}
\hline $\begin{array}{l}\text { Row } \\
\text { ID }\end{array}$ & $\begin{array}{l}\text { Number of } \\
\text { properties }\end{array}$ & $\begin{array}{l}\text { IPVA } \\
\max \end{array}$ & $\begin{array}{l}\text { IPVA } \\
\min \end{array}$ & $\begin{array}{l}\text { IPVA } \\
\text { mean }\end{array}$ & $\begin{array}{l}\text { IPVA std. } \\
\text { dev. }\end{array}$ \\
\hline 1 & 16 & 172.79 & 34.57 & 157.75 & 33.47 \\
2 & 11 & 131.33 & 3.89 & 54.01 & 37.14 \\
3 & 27 & 77.86 & 0 & 31.20 & 20.24 \\
4 & 30 & 54.26 & 0 & 10.5 & 11.78 \\
5 & 17 & 11.22 & 0 & 2.12 & 3.2 \\
Total & 101 & 172.79 & 0 & 42.68 & 56.40 \\
\hline
\end{tabular}

Horizontal and vertical errors in the lidar dataset could influence the accuracy of the IPVA ${ }^{\circ}$ on any designated structure by causing obstructing structures to have incorrect vertical and horizontal bounds, this error would then propagate into the hedonic price model. For example, an overestimation of a Gulf front property's vertical and horizontal bounds would result in properties further in-land having an artificially low view measure and the resultant hedonic model would likely produce ambiguous results when accounting for view as a component of value.

Lidar data errors originating from the instrument and the pulse's interaction with the measured surface are usually divided into random and systematic errors (Habib, Bang, Kersting, \& Lee, 2009), with the random error more difficult to isolate and control. Within this analysis, site and instrument considerations limit the extent and influence of systematic error but the random error component is uncontrolled. The vertical component of the random error is reported as an unknown component of the total RSMEz. It is worth evaluating the potential impact of the horizontal and vertical errors individually and collectively.

DGPS horizontal accuracy on a lidar survey can range from 5 to $15 \mathrm{~cm}$ (Baltsavias, 1999) and although no horizontal error is reported in the survey utilized it is known that DGPS was utilized. The actual horizontal error of the lidar and the GPS combined is likely to be greater than the vertical error but the development of a metric to measure and potentially correct this error are still in the formative stages (Habib et al., 2009). For two reasons, it is assumed that only the random error component of the horizontal accuracy will alter the accuracy of the IPVA ${ }^{\circ}$ measure and this error would only be in limited areas of topographic obstruction. Firstly, the primary obstruction of view in an urban environment is the presence of other structures. The horizontal bounds of structures in this analysis are constructed from aerial photography and survey data and not the horizontal component of the lidar data. Therefore, the GPS and lidar error is only influencing the non-structural components limiting view such as the vegetation and dune structure that in turn are a minor factor limiting view in urban environments. Secondly, systematic spatially auto-correlated GPS and lidar errors would be expected to influence similar features in a similar manner to nearby features. Within a single lidar swath operating in the same environmental conditions it is unlikely that any structure would have a vertical or horizontal error dissimilar in magnitude and direction of other nearby structures. That is, if horizontal errors introduced by GPS or lidar instrument or vertical errors introduced by the lidar instrument are present in any structure or topographic feature a similar error would be expected 
in nearby structures and features and hence the IPVA ${ }^{\circ}$ is still a precise representation of the actual viewshed.

The vertical error introduced by lidar error is the potentially more detrimental to this analysis as it is the lidar derived elevation data that attributes the horizontal building structures with height values and therefore it is the vertical error in the lidar that could potentially compromise the view calculation. Vertical lidar data errors are minimized in areas of clear canopy, limited slope and when the lidar pulse is returned from hard urban surfaces such as pavement (Hodgson \& Breshahan, 2004). The Pensacola Beach study site meets all of the aforementioned criteria for accuracy with limited tree cover, limited slope, and a majority urban or sand groundcover. The reported RSMEz of $13 \mathrm{~cm}$ at the $95 \%$ confidence interval of the utilized survey is in close agreement with other studies in similar environments that report $18.9 \mathrm{~cm}$ on pavement (Hodgson \& Breshahan, 2004) and $13 \mathrm{~cm}$ in beach environments (Huising \& Gomes Pereira, 1998). A $13 \mathrm{~cm}$ horizontal or vertical error has no potential for introducing error on the IPVA ${ }^{\circ}$ of Gulf front properties as raising the primary dune vegetation $13 \mathrm{~cm}$ and having an error in the property height of $-13 \mathrm{~cm}$ would not impact the potential view of any analyzed Gulf front structure from the upper level living space. In-land homes are more-adversely affected by the potential horizontal and vertical errors but even then the error margins are tolerable. Assuming a vertical error of $-13 \mathrm{~cm}$ on the measured structure and $+13 \mathrm{~cm}$ on the obstructing structure the effect on IPVA ${ }^{\circ}$ on the measured structure is negligible and within the bounds of the varying height of a human observer. For example, an obstructing structure that is $6 \mathrm{~m}$ in vertical height and has a maximum error of $13 \mathrm{~cm}$ would alter the total height of the structure by $2 \%$. A $2 \%$ increase or decrease in structural height causes little IPVA ${ }^{\circ}$ change for structures located one, two, three or four blocks behind the obstructing structure.

Additional horizontal and vertical errors could potentially be introduced by the interpolation process, creation of building footprints, roof structure designation and variance and by the datum accuracy at the study site. These errors are more difficult to enumerate then potential horizontal or vertical error and often require substantial field survey obtaining the exact location of building corners and then comparing these corners against the same feature in the lidar data. Again, some of these errors are limited by considerations specific to this study. Interpolation error is limited in this study by the dense nature of the survey in such that an interpolation was only required to populate very few cells within the study area. Localized datum errors are negated by the nature of the IPVA ${ }^{\circ}$ calculation as the IPVA ${ }^{\circ}$ is not sensitive to actual geodetic inaccuracies or inconsistencies, the data utilized need only be precise for accurate results to be obtained.

\section{MEASURING BEACH ACCESS}

Another essential component of the hedonic analysis is to provide a measure of actual access distance from each property to enable the implicit value of living close to the beach to be quantified. Other hedonic studies typically use the Euclidean distance from each property to the shoreline to capture access ( [Boyle and Kiel, 2001], [Parsons and Noailly, 2004], [Parsons and Powell, 2001] and [Pompe, 2008]). While this provides an appropriate approximation of access, 
it fails to truly account for the actual distance to the nearest public beach access point. For most beaches in Florida, such as Pensacola Beach, beach access is controlled and provided via signed beach access points. Within Pensacola Beach, these beach access points provide the only access to the beach, as Gulf front private property, a vegetated dune structure, and local ordinance prohibit merely crossing directly to the beach at other points. All beach access points are clearly marked and mapped by the local county.

We argue that the distance to the actual access point from each property provides a more accurate measure of beach access than the measurements used in previous studies. While, in other locations, linear distance to the amenity and the linear distance to the amenity access point can be identical or very similar, this is not the case when evaluating coastal access in Pensacola Beach. In many scenarios, homes further from the beach may actually be closer to a beach access point than homes closer to the beach. To illustrate this point, Fig. 4 depicts two properties in Pensacola Beach. Property A is approximately $210 \mathrm{~m}$ away from the shoreline and Property $B$ is only $80 \mathrm{~m}$ away from the shoreline. Despite the fact that Property $B$ is more than twice as close to the beach, Property $A$ is actually closer to the nearest public access point, and so has improved access to the beach than Property B. Property $A$ is only $134 \mathrm{~m}$ away from a beach access point, whereas Property $B$ is $295 \mathrm{~m}$ away. Traditional methods of capturing access would incorrectly imply that Property B has improved access relative to Property A. 


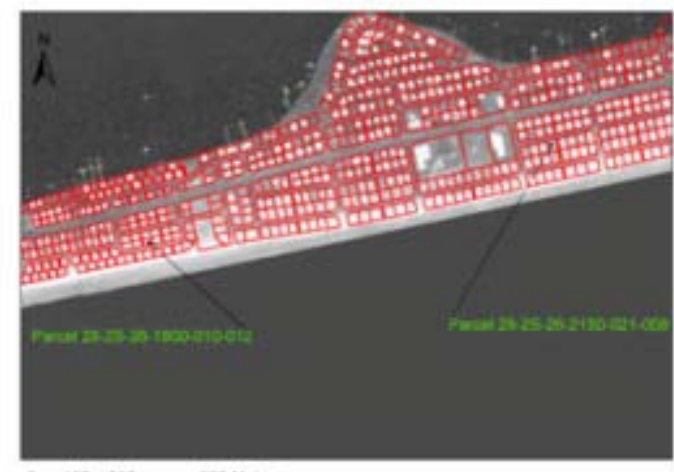

0 $150300 \quad 300$ Weters
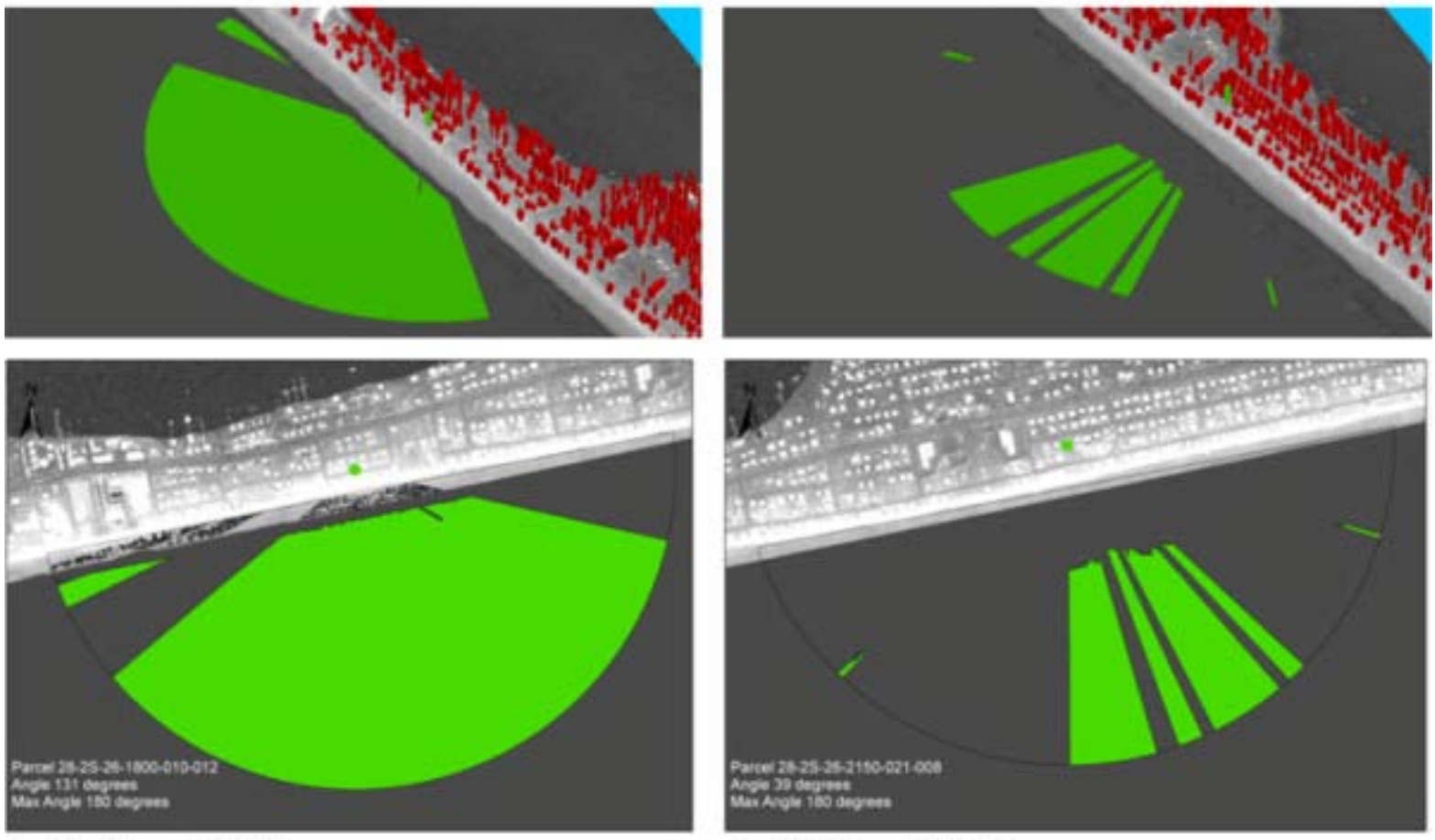

Fig. 4. Differing IPVA calculations.

Pensacola Beach Gulf access points were provided by Escambia County GIS division in September 2006 and filed verified the same month. The distance to each beach access point from each property was determined using a simple distance calculation in a GIS environment. The beach access layer was joined spatially to a point centroid of each property and a distance between the two calculated. All properties with direct access to the beach (Gulf front homes) had their distance reset to zero as they may walk directly onto the beach, but all other homes kept their distance value to the nearest access point. These data were then joined back to the property point data containing view angle information. 


\section{HEDONIC DATA}

The variables used in the hedonic property price model are shown in Table 2 together with descriptive statistics. The variables of interest are our measures of amenity value (DISTANCE and $\mathrm{VIEW}$ ). The average linear distance from each home to the nearest beach access point is $164 \mathrm{~m}$, while the average linear distance to the shoreline is $112 \mathrm{~m}$. The average property in our dataset has a 42-deg view of the Gulf. The average sales price of a home in the sample is $\$ 559,000$, while the average size of a home is 1808 square feet with two bathrooms, and 30 years of age. Approximately $8 \%$ of homes have a pool. To capture the general increase in property prices over time, we also include a time trend variable.

\begin{tabular}{|c|c|c|c|}
\hline Variable & Definition & Mean & Std. dev. \\
\hline Price & $\begin{array}{l}\text { House sales price adjusted to } 2007 \\
\text { dollars }\end{array}$ & 559306.20 & 429202.40 \\
\hline Bath & Number of bathrooms & 2.27 & 0.78 \\
\hline Sqft & Total structure square footage & 1808.00 & 657.50 \\
\hline Age & Age of house & 30.48 & 11.88 \\
\hline Pool & Pool $(=1)$ & 0.08 & 0.28 \\
\hline Time & $\begin{array}{l}\text { Time trend variable (0-9 for } 1998- \\
2007)\end{array}$ & 4.84 & 2.46 \\
\hline $\begin{array}{l}\text { Shore } \\
\text { distance }\end{array}$ & $\begin{array}{l}\text { Distance in feet to nearest beach in } \\
\text { meters }\end{array}$ & 111.90 & 74.07 \\
\hline $\begin{array}{l}\text { Access } \\
\text { distance }\end{array}$ & $\begin{array}{l}\text { Distance in feet to nearest access } \\
\text { point in meters }\end{array}$ & 163.53 & 55.20 \\
\hline View & $\begin{array}{l}\text { Angular view of Gulf from property } \\
\text { in degrees }\end{array}$ & 42.31 & 55.57 \\
\hline
\end{tabular}

\section{ECONOMIC MODEL}

In hedonic property price valuations, the price of the property is a function of the structural and locational attributes. Therefore, the relationship between property price and a property's various attributes can be expressed as:

$$
P=P(S, N, Q)
$$

where $\boldsymbol{P}$ is a vector of property sales prices, and is assumed to be a function of a vector of structural attributes, $\boldsymbol{S}$, (such as size and age of home, number of bathrooms, and so on) a neighborhood attribute, $N$, (linear distance to closest beach access point), and an aesthetic quality or coastal amenity measure, $Q$, (representing view from properties). The housing market is assumed to be in equilibrium, and so, prices are at the market clearing level. Each individual chooses a property and location by maximizing the utility function: 
(4)

$U=U(Z, S, N, Q)$

where $Z$ is a composite, representing a bundle of other goods with price equal to one, subject to a utility constraint:

(5)

$Y=P+Z$

where $Y$ is income. Taking the partial derivative of Eq. (3) with respect to each housing attribute variable yields the corresponding implicit price of the housing attribute. So, estimating the partial derivative of Eq. (3) with respect to the specific aesthetic quality attribute variable (view) yields the first-order necessary condition:

(6)

$$
\left(\frac{\partial U}{\partial q}\right) /\left(\frac{\partial U}{\partial Z}\right)=\frac{\partial \boldsymbol{P}}{\partial q}
$$

Eq. (6) represents the individual's marginal willingness to pay for a view of the Gulf.

\section{RESULTS}

In Table 3 we estimate two log linear (with the log of price as the dependent variable) models with property structural and amenity measures as the right-hand side variables. Model 1 follows the standard convention of measuring the linear distance from each property to the shoreline to provide a single proxy for a property's proximity to the resource. Model 2 includes our network access measure and provides the two separate measures for access and view to fully disentangle the amenity value. 
Table 3

Hedonic property price model results.

\begin{tabular}{|c|c|c|c|c|}
\hline \multirow[t]{2}{*}{ Variable } & \multicolumn{2}{|l|}{ Model 1} & \multicolumn{2}{|l|}{ Model 2} \\
\hline & Coefficient & Std. error & Coefficient & Std error \\
\hline Constant & $12.657^{* * *}$ & 0.292 & $12.548^{* \cdots}$ & 0.375 \\
\hline Bath & $0.137^{\cdots}$ & 0.077 & $0.151^{*}$ & 0.000 \\
\hline Sqft & $0.001^{\circ}$ & 0.000 & $0.001^{\circ}$ & 0.000 \\
\hline Age & $-0.012^{\cdots}$ & 0.004 & $-0.011^{\cdots}$ & 0.004 \\
\hline Pool & 0.065 & 0.142 & 0.090 & 0.122 \\
\hline Time & $0.087^{\cdots}$ & 0.016 & $0.095^{\cdots}$ & 0.000 \\
\hline Access & & & $-0.002^{\circ}$ & 0.001 \\
\hline View & & & $0.003^{\cdots}$ & 0.001 \\
\hline Distance & $-0.002^{* *}$ & 0.001 & & \\
\hline Obs & 101 & & 101 & \\
\hline Adjusted $R^{2}$ & 0.63 & & 0.73 & \\
\hline
\end{tabular}

- Denotes significance at the $10 \%$ confidence level.

- Denotes significance at the $5 \%$ confidence level.

-.. Denotes significance at the $1 \%$ confidence level.

Beginning with the conventional model (Model 1), the structural parameters, bath, home size, and age all have the expected statistical impact on home values. The positive coefficients on bath and sqft indicate that households are willing to pay more for larger homes and homes with more bathrooms, while the negative coefficient on AGE implies that the value of homes decrease as they age. While in some markets the age of a property may be positively correlated with price, we expected a negative coefficient on age. This is because due to the occasional tropical storm/hurricane activity experienced in the region, newer homes tend to be built to higher building code specifications, which we perceived to be of value to households. A pool has a marginal impact on property prices (perhaps not surprising given the proximity of the Gulf of Mexico). As expected, the time trend dummy is positive and significant indicating the general increase in property prices over the sample period. Finally, there is a strong negative correlation between distance to the shoreline and property values so properties closer to the beach sell for a premium, ceteris paribus, but we cannot make any further inference regarding the relative values access and view on the household's utility function.

In Model 2, the two variables of interest (ACCESS and VIEW) have the expected signs. The negative sign on the ACCESS coefficient indicates that individuals are willing to pay more for homes located closer to public access points, ceteris paribus. This result is well supported in the hedonic literature ( [Lansford and Jones, 1995], [Parsons and Noailly, 2004] and [Pompe and Reinhart, 1995]; Bin et al., 2004). Based on this result, we estimate that decreasing distance from each property to the nearest access point by $1 \mathrm{~m}$ increases property values by approximately $\$ 1119$. Bin et al. (2008) also separate viewshed and access but use a conventional linear shoreline distance measure for access in coastal community property markets across North Carolina. They find that a ten yard decrease in linear distance to the shoreline increases property values by approximately $\$ 854$.

Our results also indicate that a property's view of the resource is a significant component of a home's value, and highlights the importance of properly disentangling its effect on property 
values from an access measure. As use of lidar data allows the impact of view to be isolated in the model, the positive and significant coefficient on VIEW implies that households are willing to pay a premium for a view of the Gulf, as well as access. We find that the average household's willingness to pay for an increase in Gulf view by 1 deg is $\$ 1627$. This result is larger in value than Bin et al. (2008) estimate, who find a WTP of $\$ 995$ for a 1-deg increase in viewshed. As a priori, the hedonic specification is not known, we also ran other standard model specifications. This also provided a test for the robustness of the viewshed coefficient. The semi-log model provided the best statistical fit and the viewshed coefficient remained statistically significant under all model specifications.

Fig. 5 and Fig. 6 provide graphical representations of the relationship between our two amenity variables and property prices (without controlling for properties' structural characteristics). Data on access and view respectively are aggregated into three groups along the horizontal axes based on the lower, median, and upper quartiles of the data.

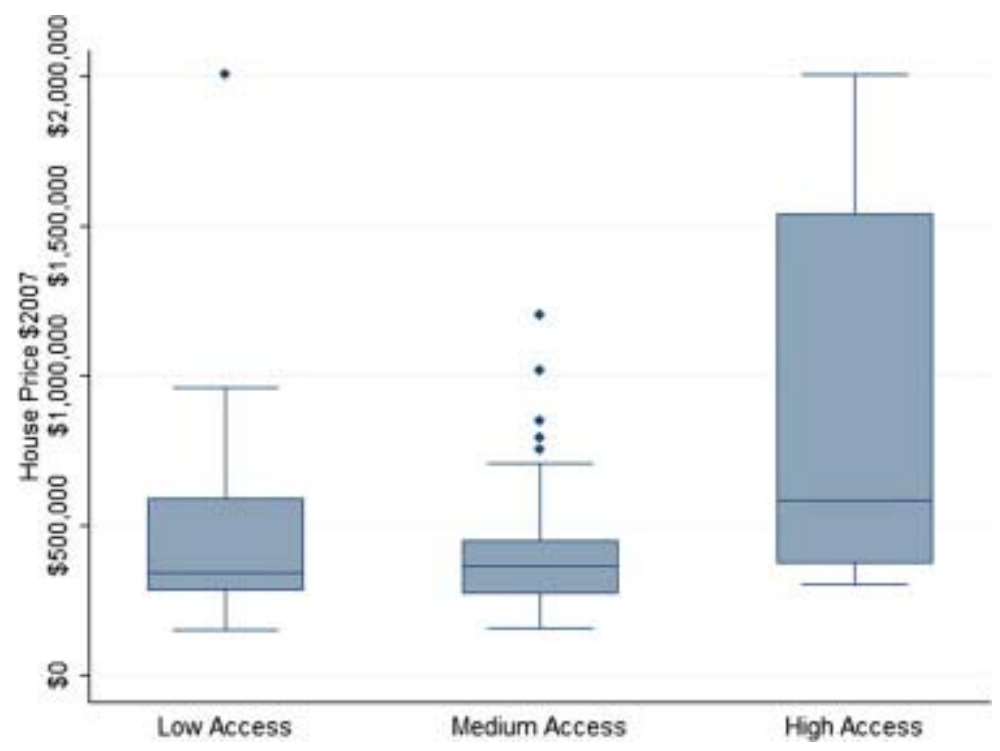

Fig. 5. Box plot of access and value. 


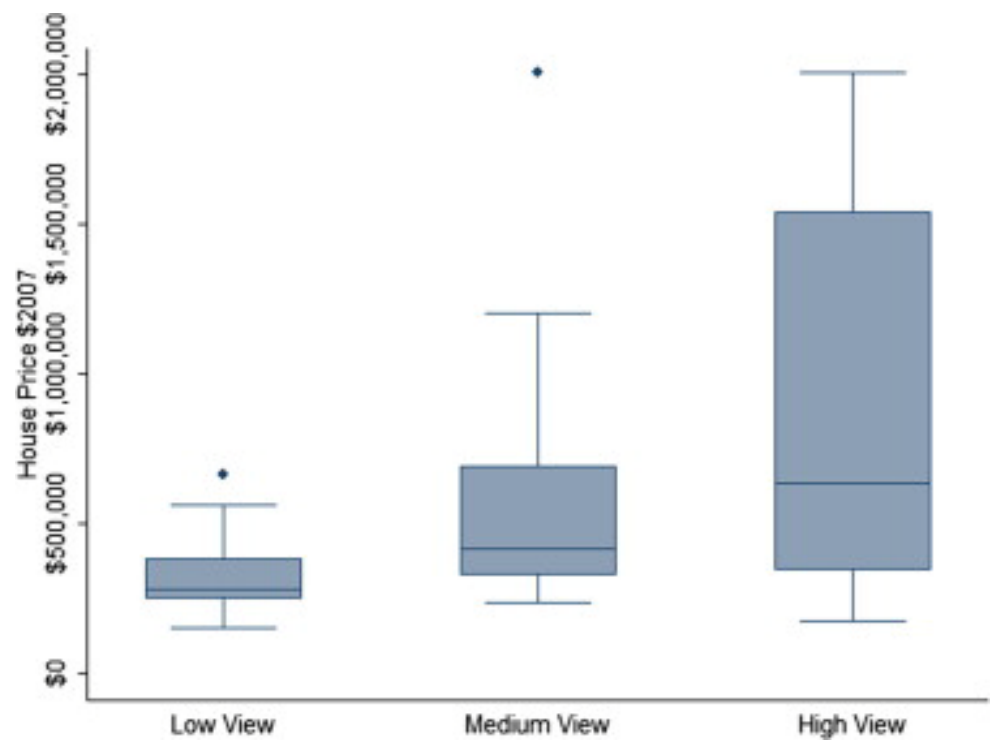

Fig. 6. Box plot of view and value.

In Fig. 5, low access refers to the lower quartile of access data. These are the properties with the least access to the beach. Conversely, high access refers to properties with the most access to the beach. Fig. 5, shows that the majority of property values for homes with low access are lower than values associated with medium and high access. Further, the median values for low access are marginally lower than for medium access, which, in turn, are far lower than for high access properties.

In Fig. 6, we can observe the relationship between low, medium, and high viewshed levels and property values, again without controlling for properties' structural characteristics.

As expected, Fig. 6 illustrates a stepwise function with the median values of properties with improved viewshed (high) higher than properties with medium and low viewsheds.

\section{CONCLUSION}

The hedonic property price literature is well versed in measuring the value of amenities. Results from these studies indicate that households are willing to pay a premium for living close to the water. While this benefit is comprised of both access value and aesthetics (view), due to limited availability of data and the problematical nature of truly capturing a property's view, earlier studies only incorporated a single distance measure as a proxy for amenity value. More recently, researchers attempted to separate the benefits of view and access by providing scope measures of the quality of a view, such as narrow, medium, and wide. While conceptually 
appealing, these measures still suffer from the subjective nature of the measurement, requiring the researcher to physically inspect the property.

Utilizing lidar GIS data to provide an objective and continuous measure of viewshed enables the access and view components of amenity value in residential coastal property markets to be fully disentangled. In the hedonic framework, having controlled for view, any residual amenity value should reflect the ease of access to the shoreline. Economic theory suggests, as individuals seek to maximize utility, they will prefer properties that provide better access to the shoreline, all else being equal. While it is common in hedonic modeling to capture access as the linear distance from each property to the shoreline, many residential coastal communities have beachfront private property, and/or a vegetated dune structure, and/or local ordinance that restricts access to non beach-front homes to state-designated public access points. In these communities, true access is provided by the linear network distance from each property to the nearest designated access point.

Our research examines how individuals evaluate access in their property purchase decision for such communities. Results from our semi-log hedonic model that includes separate measures of access and viewshed indicate that households are willing to pay a premium of $\$ 1119$ for a $1 \mathrm{~m}$ decrease in distance to the shoreline and \$1627 for a 1 deg increase in viewshed of the shoreline. Overall, we believe that this paper provides a platform for further exploration into appropriately disentangling access and viewshed in hedonic studies designed to capture amenity values.

\section{REFERENCES}

Baltsavias (1999). Airborne laser scanning: Basic relationships and formulas. Photogrammetric Engineering and Remote Sensing, 54, 199-214.

Bensen, E. D., Hansen, J. L., Schwartz, A. L., \& Smersh, G. T. (1998). Pricing residential amenities: The value of a view. Journal of Real Estate Finance and Economics, 16, 55-73.

Bin, O., Crawford, T. W., Kruse, J. B., \& Landry, C. E. (2008). Viewscapes and flood hazard: Coastal housing market response to amenities and risk. Land Economics, 84(3), 434-448.

Bin, O., \& Kruse, J. B. (2006). Real estate market response to coastal flood hazards. Natural Hazards Review, 7(4), 137-144.

Bin, O., \& Polasky, S. (2004). Effects of flood hazards on property values: Evidence before and after hurricane floyd. Land Economics, 80, 490-500.

Bond, M. T., Seiler, V. L., \& Seiler, M. J. (2002). Residential real estate prices: A room with a view. Journal of Real Estate Research, 23, 129-137. 
Bourassa, S. C., Hoesli, M., \& Peng, V. S. (2003). Do housing submarkets really matter. Journal of Housing Economics, 12, 12-28.

Boyle, M. A., \& Kiel, K. A. (2001). A survey of house price hedonic studies of the impact of environmental externalities. Journal of Real Estate Literature, 9, 117-144.

Deronde, B., Houthuys, R., Debruyn, W., Fransaer, D., Lancker, V.V., Henriet, J.P. Use of airborne hyperspectral data and laserscan data to study beach morphodynamics along the Belgian Coast. Journal of Coastal Research 22(5), 1108-1117.

Doss, C. R., \& Taff, S. J. (1996). The influence of wetland type and wetland proximity on residential property values. Journal of Agricultural and Resource Economics, 21, 120-129.

Habib, A., Bang, K. I., Kersting, A. P., \& Lee, D. C. (2009). Error budget of lidar systems and quality control of the derived data. Photogrammetric Engineering and Remote Sensing, 75, 1093-1108.

Hodgson, M. E., \& Breshahan, P. (2004). Accuracy of airborne lidar-derived elevation: Empirical assessment and error budget. Photogrammetric Engineering and Remote Sensing, 70, 331-339.

Houser, C., \& Hamilton, S. (2009). Sensitivity of post-hurricane beach and dune recovery to event frequency. Earth Surface Processes and Landforms, 34, 613-628.

Houser, C., Hapke, C., \& Hamilton, S. (2008). Controls on coastal dune morphology, shoreline erosion and barrier island response to extreme storms.

Geomorphology, 100, 223-240.

Huising, E. J., \& Gomes Pereira, L. M. (1998). Errors and accuracy estimates of laser data acquired by various laser scanning systems for topographic elevations. Photogrammetric Engineering and Remote Sensing, 53, 245-261.

Lansford, N. H., \& Jones, L. L. (1995). Marginal price of lake recreation and aesthetics: An hedonic approach. Journal of Agricultural and Applied Economics, 27, 212-223.

Morgan, O. A. (2007). The impact of hurricane ivan on expected flood losses, perceived flood risk, and property values. Journal of Housing Research, 16(1), 47-60.

NOAA (2007). 2006 Florida Lidar: Escambia, Santa Rosa, and Walton Counties metadata <http://www.csc.noaa.gov/ldart>.

Parsons, G. R., \& Noailly, J. (2004). A value capture property tax for financing beach nourishment projects: An application to Delaware's ocean beaches. Ocean and Coastal Management, 47, 49-61.

Parsons, G. R., \& Powell, M. (2001). Measuring the cost of beach retreat. Coastal Management, 29, 91-103. 
Paterson, R., \& Boyle, K. (2002). Out of sight, out of mind? Using GIS to incorporate visibility in hedonic property value models. Land Economics, 78(August),

417-425.

Pompe, J. J. (2008). The effect of a gated community on property and beach amenity valuation. Land Economics, 84(3), 423-433.

Pompe, J. J., \& Reinhart, J. R. (1995). Beach quality and the enhancement of recreational property values. Journal of Leisure and Research, 27(2), 143-154.

Tse, R. Y. C. (2002). Estimating neighborhood effects in house prices: Towards a new hedonic model approach. Urban Studies, 39, 1165-1180.

Wehr, A., \& Lohr, U. (1999). Airborne laser scanning - An introduction and overview. ISPRS Journal of Photogrammetry and Remote Sensing, 54, 68-82. 